\title{
Akran Zorbalığını Önlemede Hemşirenin Rolü
}

\author{
Role of Nurse in Peer Bullying Prevention
}

\author{
Gülümser DOLGUN ${ }^{\mathrm{a}}$
}

\begin{abstract}
ÖZ Akran zorbalığı okullarda her geçen gün artan, kısa ve uzun dönemde insan sağlığını olumsuz yönde etkileyen bir halk sağlığı sorunu olarak tanımlanmaktadır. Akran zorbalığı, güçlünün zayıf üzerinde kasıtlı ve sürekli olarak fiziksel, sözel, davranışsal güç kullanmasıdır. Bu durum, öğrenciler için ciddi bir travma olup, etkileri okul dönemi ile sınırlı kalmayıp yaşam boyu sürmekte ve toplum sağllğını da olumsuz etkilemektedir. Akran zorbalığı sadece öğrencileri değil aileleri, öğretmenleri ve okul yöneticilerini de olumsuz etkiler. Akran zorbalığının önlenmesi; eğitim ve toplumun tüm paydaşlarını (öğrenci, öğretmen, yönetici, veli, hemşire, sivil toplum örgütleri) içine alan, etkili politikaların geliştirilmesi ile mümkündür. Toplumda; her çocuğun güvenilir bir ortamda eğitim, öğretim alma ve yaşam hakkı olduğu gibi temel insani değerler ve farklılıklara saygı duyma konusunda bilinç kazandırılması önemlidir. Bu yazıda akran zorbalığının tanımı, zorbalığın çocuk sağlığı ve akademik başarıya etkileri ve akran zorbalığını önleme ve müdahale programlarının geliştirilmesinde, halk sağlığı ve okul hemşiresinin rolleri ele alınacaktır.
\end{abstract}

Anahtar sözcükler: Akran zorbalığı; mağdur; okul hemşireliği; önleme stratejileri

\begin{abstract}
Peer bullying is defined as a problem of public health that affects human health negatively in the short and long term, increasing day by day in schools. Peer bullying is the use of force by intentionally and constantly physical, verbal, behavioral power over the weak. This situation is a serious trauma for the students and the effects are not only limited to the school period but also life-long and also affect the public health negatively. Peer bullying negatively affects not only the students but also their parents, teachers and school administrators. Peer bullying can be prevented by the development of effective policies that include education and the community's stakeholders (students, teachers, administrators, parents, nurses, non-governmental organizations). In society; it is important that every child receive education, training, in a reliable environment, and given awareness of respect for basic human values and differences as well as the right to life. In this article will focus; the definition of peer bullying, the effects of bullying on children's health and academic achievement; and the role of public health and school nurses in the development of prevention and intervention programs for peer violence.
\end{abstract}

Key words: Peer bullying; victim; school nurse; prevention strategies

\section{Giriş}

Zorbalık, tüm dünya da anaokulundan başlayarak hayatın her alanında, mahalle, sokak, spor alanı, okul ve iş yerlerinde sağlığı ciddi bir bicimde tehdit eden bir halk sağlik sorunudur. Zorba davranışlar farklı şekillerde; fiziksel, sözel, cinsel, homofobik, dinsel, irksal ya da siber saldırı olarak yaşanabilmektedir. Ebeveynlerin ve okul yöneticilerinin anlık kaygıları kadar olayın zorba ve mağdur üzerindeki olumsuz etkilerinin ileri yaşlarda devam etmesi, sağlık çalışanlarının problem üzerinde sürekli çalışmasını gerektirmektedir. ${ }^{1,2}$ $\mathrm{Bu}$ yazı ile çok boyutlu, geniş kapsamlı olan ve önlenmesi için multidispliner çalışma gerektiren akran zorbalığında; olayın zorba, mağdur ve izleyiciler üzerindeki etkilerine dikkat çekilmiş ve hemşirenin rolü üzerinde durulmuştur. Çünkü hemşireler sağlık sorunlarının belirlenmesinde ve önlenmesinde çocuk ve aile ile ilk karşılaşan sağlık ekibi üyesidir. Bu bağlamda bir halk sağlığı sorunu olarak görülen akran zorbalığında özellikle toplum ve okul sağlığı hemşireliğinin rolleri üzerinde durulacaktır.

\section{Konunun Tanımı ve Önemi}

Zorbalık, 1970'lerin sonunda Olweus tarafindan tanımlanmış ve genellikle agresifliğin/ saldırganlığın bir alt kategorisi olarak kabul edilmiştir. Dilimizde saldırganlık, şiddet ve zorbalık kelimeleri eş anlamlı olarak kullanılmaktadır. Oysa gerçekte anlamları son derce farklıdır. Şiddet (violence), eylemin kendisini tanımlamak için kullanılır ve fiziksel güç kullanmayı gerektirdiği için yaralanma ve ölümle sonuçlanabilir. ${ }^{2,3}$ Saldırganlık şiddeti ve zorbaca eylemleri içine alan bir kavramdır. Şiddet ve zorbalıktan farkı; kişinin psikolojik ve toplumsal gelişiminin, nörolojik ve hormonal yapısının

Geliș Tarihi/Received:19-08-2017/ Kabul Tarihi/Accepted:7-12-2017

a Doç. Dr. İstanbul Üniversitesi Sağlık Bilimleri Fakültesi, Ebelik Bölümü, e-mail: gulumser6@ hotmail.com ORCID: 0000-0003-2988-9280 
etkileşimiyle ortaya çıkmasıdır. Bu nedenle daha çok dürtü, içgüdü olarak tanımlanır ve kişisel, toplumsal ve çevresel özelliklere göre değişiklik gösterir. Saldırganlık her zaman şiddete dönüşmeyebilir ya da zarar verme amaciyla gerçekleşmeyebilir. Bazen özgürlük, statü kazanımı gibi nedenlerle yapılan saldırganlık hoş karşılanır, hatta ödüllendirilir. ${ }^{4,5}$ Zorbalık (bullying), bir tür saldırganlık olmakla birlikte sadece "saldır-ganlık" özelliği taşımamakta ya da sadece "şiddet" içerme-mektedir. Zorbalık, herhangi bir kışkırtma olmaksızın, gerçek ya da algılanan güç dengesizliği olan kişi ya da grubun, tekrarlayıc1, sistematik zarar verme davranışı olarak adlandırılmaktadır. Şiddet, bir defaya mahsus olabildiği gibi güç dengesi de aramaz. ${ }^{6,7}$ Akran zorbalığını ve içinde gecen diğer terimleri iyi anlayabilmek ve ortak terminoloji kullanmak içi anlamını net olarak açıklamak gerekir.

Akran zorbalığı (peer bullying): Zorbalık her yaşta kişi tarafindan uygulanabilir. İlk kez Norveçli araştırmacı, Dan Olweus tarafından daha çok çocuk ve adolesanlar için kullanılan bir terimdir. Tanımı zorbalık ile benzerdir. Aynı ya da benzer yaştaki akranların; kışkırtma unsuru olmaksızın, aralarında fiziksel, psikolojik açıdan güç eşitsizliği olan bireylerden güçlünün, karşı tarafa bilerek, isteyerek, kasitlı olarak ve sistemli bir biçimde uyguladığı, aynı kişi ya da gruplar arasında tekrarlılık gösteren, mağdur olanda korku, endişe yaratmayı amaçlayan fiziksel, sözel, psikolojik saldırı veya yıldırmayı içeren olumsuz davranışlar olarak tanımlanır. ${ }^{6,8}$ En önemli özelliği tekrarlayıcı olması ve karşı tarafta sürekli bir mağduriyet içermesi ve zorba ile mağdur arasında sürekli, dinamik bir ilişki olmasidir.

Mağdur/kurban (victim): Başka bir kişi ya da kişilerin hareketlerinden, davranışlarından, sözlerinden, düzenli olarak zarar görmüş, ac1 çekmiş ve genelde zayıf, savunmasız, itaatkar kişidir. Obezite, sakatlık, etnisite farklılığı, düşük sosyo-ekonomik durum gibi sosyal statü kayıpları vardır. ${ }^{9} \mathrm{Bu}$ nedenle bazı çocukların mağdur olma olasılığı diğerlerine göre daha yüksektir. Mağdurlar genelde pasif kişilik özelliklerine sahiptir. Bazen tam tersi aktif, asabi, uyumsuz ve kışkırtıcı da olabilir ve saldırıya uğradıklarında misilleme yapabilirler. ${ }^{8,10}$
Zorba-Kurban (provokatif kurban): Hem zorbaca söz ve eylemlerde bulunma, hem de zorbalığa maruz kalma anlamında kullanılır. Bu kişiler agresif, ateşli, huzursuz ve yıkıcı olarak tanımlanır.10 Mağdurların okul performansının düşmesi, psikolojik sorunlar yaşamaları sonucu zaman içinde zorba olma olasılıkları nedeniyle her iki grubun da teşhis edilmesi önemlidir. Burada Olweus "bullying circle-mağdur-kurban çemberi" den söz etmektedir. ${ }^{8,10}$

İzleyiciler/tanıklar: Araştırmalarda izleyiciler dört grupta ele alınmaktadır. Olaylara karışmayan fakat zorbanın tarafinda olup, bu durumu destekleyen itaatkar/aktif izleyiciler: İtaatkar izleyiciler bazen zorbanın davranışlarını kolaylaştırmak içi uygun ortam yaratır. $\mathrm{Bu}$ şekilde davranmakla gücü olan zorbanın yanında bir sosyal statü ya da maddi çıkar elde etmekte ve kendilerini güvenceye aldıklarını düşünmektedirler. $\mathrm{Bu}$ grupta olan izleticiler daha sonra zorbalık yapabilir ya da kendilerini kötü hissedebilirler. Zorbaların savunucu izleyicilerden kendilerini korunmak için onları destekleyen itaatkar izleyicilere gereksinimleri vardır. Asistan tip katılımcılar: Fiziksel olarak zorbaya yardım etmekte, bir nevi yardımcı rolü üstlenmektedirler. Savunucu izleyiciler; zorbanın yaptıklarına karşı kurbanın yanında olurlar fakat aktif değildirler. Genellikle mağ-durla aynı cinsiyettedir. Savunucu izleyiciler mağduru savunurken kendileri de zorbaya karşı motive olup, güç toplar. Çünkü bir sonraki hedefin kendileri olabileceğinden korkar ve endişe duyarlar. Mağdurların savunulması önemlidir. Çünkü zorbalar arkasında savunu-cusu olanları hedef almak istemezler., ${ }^{911}$ Bir de durumu ne provoke eden ne de mağduru savunan fakat kısmen bu olaydan zevk alan tarafsiz-pasif izleyiciler vardır. $\mathrm{Bu}$ kişiler olayın onları ilgilendirmediğini düşünür, fakat hem zorba hem de mağdurlar bu kişileri karşı tarafin destekleyicisi gibi algıladığından, geleceklerinden endişe duyarlar (Resim 1). ${ }^{8}$ Akran zorbalığ 1 , zorbanın, mağdurun ve izleyicilerin fiziksel, ruhsal sağlığını ve yaşam kalitesini olumsuz etkileyen önlenmesi gereken, başı sonu belli olmayan dairesel bir süreçtir. Hiç kimse olayın dışında kalamamaktadır. Tüm bu karşılıklı ilişkilerde akranlar kadar aile ve okul personelinin tavrı ve durduğu yer de önemlidir. ${ }^{8,11}$ 


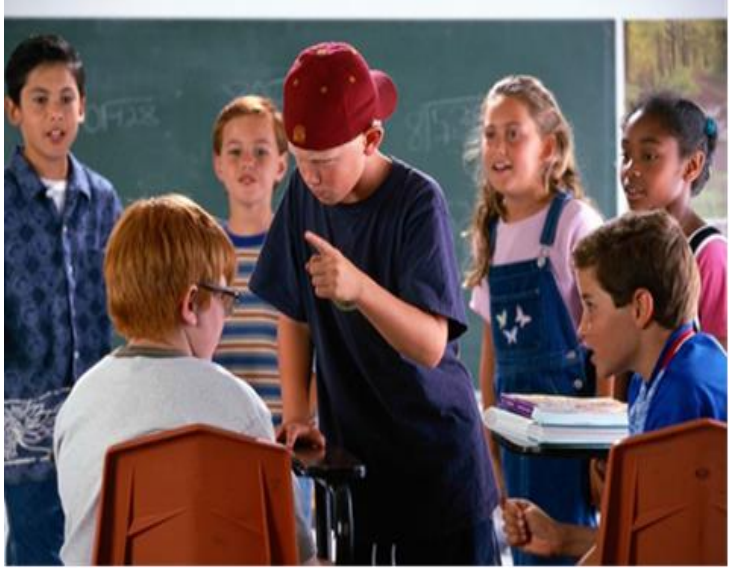

Resim 1: Akran Zorbalığ1 ve İzleyiciler

SW Productions/Photodisc/Getty Images (19.07.2017 alındı) https://www.verywell.com/characteristics-of-a-typicalvictim-of-bullying-3288501

\section{Sıklığı}

Zorbalık, çocuklar ve adolesanlar için en zor deneyimlerden biridir. S1klığının 8-16 yaşları arasında artığı, yaş artıkça adolesanın kendini koruması artıkça azaldığı, fakat etkilerinin yetişkin döneminde de devam ettiği gösterilmiştir. ${ }^{12,13}$ Kapç$^{14}$ yaptığ 1 araştırmada, ilköğretim 4. ve 5. sinıfa devam eden öğrencilerin \% 40'ının en azından bir kere fiziksel, sözel, duygusal ya da cinsel akran zorbalığı ile karşılaştığını belirtmiştir. Bir kısım araştırmacı da zorbalığın farklı türlerine maruz kalmanın yaşa göre değiştiğini genel olarak fiziksel zorbalığa maruz kalmada yaşa bağlı bir düşüş gözlendiğini, ilişkisel zorbalığa maruz kalmada bir artışın görülebileceğini ortaya koymuştur. ${ }^{13}$ Cinsiyetlere göre akran zorbalığına bakıldığında; araştırmaların çoğunda erkeklere daha çok fiziksel saldırganlık uygulandığ 1 , kızların ise dolaylı saldırganlığa (sözel, psikolojik) maruz kaldıkları görül- mektedir. ${ }^{12,13}$ Zorbalıkta yaş ve cinsiyet etkenlerinin dışında; okul değişikliği, fazla kilolu, farklı cinsel eğilimleri olma gibi bağlamsal faktörlerin de etkili olduğu ve zorbalık davranışlarının daha çok okul içinde görüldüğü belirtilmektedir. ${ }^{15,16}$

\section{Zorbalık Türleri, Yöntemleri ve Karakteristik Özellikleri}

Araştırmalar zorbalığı, doğrudan ve dolaylı diye iki ana gruba, kullanılan zorbalık yöntemine göre de alt gruplara ayırmaktadır $^{2,15,17}$ (Tablo 1). Akran zorbalığını yapan ve mağdur olanların farklı karakteristik özellikleri olmasına rağmen ${ }^{2,18}$ (Tablo 2) uzun dönem etkileri genellikle ortaktır. Her ikisinde de adolesan ve yetişkinlerde alkol ve diğer ilaçları kötüye kullanımı, okuldan ayrılma, depresyon, erken cinsel aktivitede bulunma ve yetişkinlikte cezai mahkumiyet, trafik cezaları aldıkları belirtilmektedir. ${ }^{19}$

\section{Akran Zorbalığının Önlenmesinde Hemşirenin Rolü}

Zorbalık geniş, kapsamlı, çok boyutlu ve önlenmesi için birçok disiplinin birlikte çalışmasını gerektiren bir halk sağlığ olarak görülmektedir. Okul ve toplum sağlığ1 hemşireleri, çocuk ve adolesanın fiziksel, psikososyal tanılanması ile akran zorbalığını belirlemede en iyi konumda olan sağlik elamanlarıdır. En önemlisi de fiziksel zorbalıklarda ilk acil yardımı yapan ilk kişi olmalarıdır.

Hemşireler, öğretmenler ve veliler gibi çocuğun okul performansı ile doğrudan ilişkili olmadığı için adolesan ile daha kolay güven ilişsisi kurabilir ve zorbalık döngüsünü durdurmasina ya da azalmasina yardıme olabilirler.

Tablo 1: Zorbalık Türleri ve Yöntemleri

\begin{tabular}{ll}
\hline Zorbalık Türleri & Zorbalık Yöntemleri \\
\hline Fiziksel zorbalık (doğrudan) & Vurmak, itmek, kurbanın bir şeylerini çalmak, kişiye ve eşyalarına zarar \\
\hline Sözlü zorbalık (doğrudan) & $\begin{array}{l}\text { İftira atmak, isim takmak, hakaret etmek (ailesine, dinine, rrkına), tehdit } \\
\text { etmek, alay etmek, kelimelerle psikolojik yıldırma uygulamak }\end{array}$ \\
\hline İlişkisel zorbalık (dolaylı) & $\begin{array}{l}\text { Dedikodu yapmak, saygısız hareketler yapmak, akranların mağdur ile ilişki } \\
\text { kurmasını engellemek }\end{array}$ \\
\hline Siber zorbalık (dolaylı) & $\begin{array}{l}\text { Elektronik ortamı kullanarak tehdit, taciz, içeren yazılar, çizimler göndermek, } \\
\text { alay etmek ve gözdağı vermek }\end{array}$ \\
\hline
\end{tabular}


Tablo 2: Zorba, Mağdur ve Zorba/Mağdurların Karakteristik Özellikleri

\begin{tabular}{lll}
\hline Zorba & Mağdur & Zorba/Mağdur \\
\hline Dominant karakter & Fiziksel olarak akranlarından & Dürtüsel davranışlar \\
\hline Genellikle erkek & Düşük benlik saygısı & Düşük benlik saygısı \\
\hline Karşı çıkma davranışları & Arkadaş edinme güçlükleri & Düşük sosyal beceriler \\
\hline Madde, alkol, sigara kullanımı & $\begin{array}{l}\text { Arkadaşlarından daha az } \\
\text { iddialı }\end{array}$ & Düşük problem çözme becerisi \\
\hline $\begin{array}{l}\text { Eşlik eden durumlar (DEHB*, } \\
\text { depresyon, karşıt olma/karşı } \\
\text { gelme bozukluğu) }\end{array}$ & $\begin{array}{l}\text { Eşlik eden durumlar } \\
\text { (anksiyete, kaygı, yalnızlık, } \\
\text { depresyon) }\end{array}$ & $\begin{array}{l}\text { Eşlik eden durumlar (DEHB, depresyon, } \\
\text { karşıt olma / karşı gelme bozukluğu) }\end{array}$ \\
\hline
\end{tabular}

* Dikkat Eksikliği Hiperaktivite Bozukluğu (DEHB)

Akran zorbalığının daha çok okulda, sınıfta veya okul yolunda olması nedeniyle araştırmalar daha çok okul hemşireliği ile ilgilidir. Fakat okul hemşireliği de iş yeri hemşireliği gibi toplum sağlığı hemşireliğinin içinde yer almaktadır. ${ }^{20,21}$ Ayrıca, okul ve toplum sağlı̆̆ hemşireleri baş ağrısı, kusma, uyku düzensizleri, konsantrasyon güçlükleri, idrar problemleri (tutamama, enürezis), gece kabusları gibi bedensel stres belirtileri nedeni ile sik sik okula gitmek istemeyen, devamsızlık yapan ve zorbalığa maruz kalan çocukları daha kolay tanılayabilir. Hemşireler zorbayı ve mağduru tanılamak için çocuklara dolaylı sorular yönetmeli; "okulda işlerin nasıl gittiği, okula gitmekten hoşlanıp hoşlanmadığı, arkadaş ilişkilerini, grup oyunlarına katılıp katılmadığını, bu oyunlara arkadaşları $\mathrm{mi}$ onu seçiyor yoksa o mu arkadaşlarını belirliyor, bilgisayar ve telefon kullanıp kullanmadığı" gibi ve aldığı cevapları değerlendirip, karar vermelidir. Mağdurları belirlemede; fiziksel morluklara, yırtık giysileri ya da aileden sürekli para isteyip istemediği, değerli giysi veya aksesuarlarını (ayakkabı, saat, kravat gibi) sik kaybedip etmediğinin sorgulanması tanıda yardımcıdır. ${ }^{2,21}$ Amerikan Pediatri Birliği'nin ${ }^{22}$ ve Ulusal Okul Hemşireleri Birliği'nin, ${ }^{23}$ okulda şiddet olaylarında okul hemşirelerinin sorumluluklarını içeren raporları yayınlanmıştır.

$\mathrm{Bu}$ raporlarda okul hemşiresinin sorumlulukları şöyle özetlenmektedir:

- Riskli aile ve çocukların tanılanması,

- Öğrenci, aile, okul çalışanlarının eğitimi,

- Pozitif rol modeli olma,

- Okuldaki çocuklara güvenli okul çevresi sağlamada gerekli yasal aktivitelere katılma,
- Çocukların benlik saygılarını geliştirmeye yönelik girişimde bulunmadir.

Zorbalıkta okul hemşiresinin rolü dört boyutta tanımlanmıştır: ${ }^{24}$

- Tanılama yapması; davranışın tanilanmasi,

- Danışmanlık yapması; okul ve aile ile işbirliği yapılarak zorbalığın önlenmesine yönelik programların uygulanmaS1,

- Önleyici olması; sağlığı koruma ve geliștirmeye yönelik programların uygulanmas1,

- Bilimsel araştırmalar yapması; yeni ölçüm araçlarının geliştirilmesi, zorbalığın önlenmesine yönelik girişimlerin ve stratejilerin uygulanmasıdır.

Akran zorbalığının, toplumsal yaşantının sürdürüldüğü her ortamda önemli bir sorun olması ve bu sorunla ebeveynlerin tek başlarına baş etmeleri oldukça zor olması nedeniyle aile ve sosyal ortamları ayrı ayrı düşünülmemelidir. Okul hemşiresi okulda çocuklar, aileleri ve okul çalışanları ile işbirliği içinde olmalı ve kaynaklarını okuldaki öğrencilerin sağlığını geliştirmeye yönelik kullanmalıdır. ${ }^{24}$ Okul hemşiresi, zorba veya kurban öğrencilerin belirlenebilmesi için rehberlik bölümü, eğitimciler, aileler, ögrenciler ve okul personeli ile birlikte hareket etmelidir. Öncelikle orta ve uzun vade zorbalığı önleme programları yapılmalı ve bu programların sürekliliği sağlanmalıdır. Çünkü sorun bir öğrencinin, ailenin, okulun sorunu değil toplumsal bir sorundur. $^{25,26}$ Eğitimde öncelikli hedef zorbalığın olumsuz etkilerinin tanıtılması ve insanların zorbalığa ilişkin yanlış inanışlarını 
ortadan kaldırılmasıdır. O'Moore ${ }^{26}$, bu yanlış inanışları şöyle sıralamıştır:

- Okulda zorbalığa maruz kalmak, hiç kimseye hiçbir şekilde zarar vermez.

- Zorbalık büyümenin normal bir parçasıdır.

- Zorbalik bir karakter oluşturma sürecidir.

- Zorbalık çocuğu adam eder.

- Sopa ve taş bir kişinin boynunu kırabilir ama kelimeler hiç kimseyi yaralamaz.

- Kimseye söyleme yoksa suçlu (ispiyoncu, gammazc1) sen olursun.

$\mathrm{Bu}$ yanlış inanışlar, zorbalığın önlenmesini güçleştirmektedir. İlk aşamada bu konuda verilecek eğitimler, demeçler, bilgilendirme programları ile farkındalık oluşturarak medyanın, politikacıların ilgisi sürekli diri tutulmalı, yeni sorunların gelişmesi önlenmelidir. Eğitimler öğrencileri yașına, ailelerin etnik gruplarına uygun olmalıdır. Aile, ögrenciler ve okul personeli konu ile ilgili farkındalık edindikten sonra, zorba ve kurbanların bireysel ihtiyaçlarının neler olduğunu saptamak ve bu ihtiyaçları karşılamak zorbalığı önleme çalışmalarında ikinci adımdır. ${ }^{27}$ Bunun için çeşitli anket ve testlerden yararlanılabilir. Sonra da bu ihtiyaçlarının karşılanması için; okulda orta ve uzun vadeli stratejik politikalar oluşturulmalı, akran grupları ve aileler sosyal yapilar ile desteklenmelidir. Aile tutumlarının önemi vurgulanmalı; aşırı, sert disiplinin veya denetim eksikliğinin, sınırsız özgürlüklerin çocukta güven ve aidiyet duygularını olumsuz etkilediği anlatılmalıdır. ${ }^{28}$ Çocuklarına karşı açık olmaları, onlar ile zaman geçirmeleri ve desteklemeleri önerilmelidir. Aile özellikleri; ailenin çocuk yetiştirme tutumları ve aileye bağlanma davranışları zorbalıkta araştırılması gereken davranışlardır. ${ }^{11,27}$ Öğrenmelere bireysel farkındalıkların kabulünü artıran, sınıf ruhunu geliștiren, öğrencilerin farklı özelliklerini ön plana çıkarabilecekleri ortamlar oluşturan yardımcı faaliyetlere ağırlık vermeleri önerilmektedir. Ayrıca güvenli okul ve sınıf olușturulması önemlidir. Bunun için de aile, okul ve sosyal ortamları içeren bütüncül programlar oluşturulabilir. ${ }^{29}$ Bütüncül programların başarısının sırrı dört madde ile özetlenmektedir: Çocuklar ile olumlu, sıcak bir ilişki ile onların yaşamına dahil olmak, kabul edilemez olan davranışlara kesin sınır koymak, kuralları bozan çocuklara fiziksel ve düşmanca olmayan tavir sergilemek ve sorumluların olumlu rol model olmas1 olarak gösterilmektedir. Bu konuda tüm tarafları içeren komitelerin kurulması, herkesin uyacağ 1 kuralların net belirlenmesi ve bunların her seviyede kişi, sınıf ve gruplara uygulanması ve zorbalıkla ile ilgili karşıt kampanyalar düzenlenmesi, programların başarısını ölçmek için araştırmalar yapılması önerilmektedir. ${ }^{30,31}$ Hemşire tutarlı ve güven verici davranışları ile zorbalıkla karşılaşmanın utanç verici bir durum olmadığını adolesana hissettirmelidir. Çünkü çocuklar, zorbalığa maruz kaldıklarında, bir dışlanmışlık duygusu yaşarlar ve uygun bir yetişkin desteği aramayabilir ya da mağdurluğun açıklanmasını utanç verici bulabilirler. Hemşireler, adolesanların şüphe ve endişelerini giderici açıklamalar yapmalı ve onları mümkün olduğunca koruyucu davranışlar göstermelidir. ${ }^{32}$

\section{Sonuc}

Zorbalık, karmaşık, çocuk sağlığı üzerinde kısa ve uzun vadeli ciddi ruhsal ve fiziksel etkileri olan zor bir konudur. Mağdurların desteklenmesi, zorbaların açığa çıkması için cesaretlendirilmesi önemlidir. Çocukların kendini güvende hissetmesi için öğrencilerin, ailelerin, okul çalışanlarının eğitilmesi ve zorbalığa karşı farkındalık oluşturulması, yüksek risk oluşturan grupların belirlenmesi, aktif bir mücadele programının geliştirilmesi ve hayata geçmesini sağlamak okul ve halk sağlığ1 hemşirelerin sorumlulukları arasındadır. Ayrıca okulda akran zorbalığını önlemeye yönelik olarak; öğrencilerin iletişim becerilerini artırmaya, duygularını sözel olarak ifade edebilmeleri ve enerjilerini dışa vurmaya yönelik çeşitli sosyal, kültürel veya spor etkinliklerine ağılık verilmelidir. Böylece çocukların, toplumda yer edinmek için daha olumlu yolların olduğunu fark etmeleri sağlanmalıdır.

\section{Kaynaklar}

1. Pells K, MJ. Ogando P. Revollo E. Experiences of peer bullying among adolescents and associated effects on young adult outcomes: longitudinal evidence from ethiopia, india, peru and viet nam, innocenti discussion paper, UNICEF Office of Research - Innocenti, Florence. 2016. p.1017.

2. Shetgiri R. Bullying and victimization among children. Advances in Pediatrics 2013;60(1):33-51. 
3. Göker R. Okullarda akran zorbalığı [Peer bullying in schools]. Uluslararas1 İnsan Bilimleri Dergisi [Journal of Human Sciences] 2009;(2):511-37.

4. Salmivalli C. Bullying and the peer group: a review. Aggression and Violent Behavior 2010;15(2):112-120.

5. Olweus D. Bullying at school: what we know and what we can do. Cambridge MA: Blackwell, 1993. p.8-13.

6. Finkelhor D, Turner HA, Hamby S. Let's prevent peer victimization, not just bullying. Child Abuse \& Neglect. 2012;36(4):271-74.

7. Olweus D. Sweden. In Smith PK, Morita Y, Junger-Tas J, Olweus D, Catalano R, Slee, P. (Eds). The nature of school bullying: a crossnational perspective. London \& New York: Routledge, 1999. p.7-27.

8. Saleh MB. The hero as a victim of bullying and mobbing: a critical analysis of john steinbeck's of mice and men. International Journal of Humanities and Social Science 2013;3(1):139-46.

9. Huitsing Snijders TA, Van Duijn MA, Veenstra R. Victims, bullies, and their defenders: a longitudinal study of the coevolution of positive and negative networks. Development and Psychopathology 2014;26(3):645-659.

10. Solberg ME, Olweus D, Endresen IM. Bullies and victims at school: are they the same pupils? British Journal of Educational Psychology 2007;77:441-464.

11.Nickerson AB, Mele D, Osborne-Oliver KM. Parent-child relationships and bullying. In Jimerson SR, Swearer SM, \& Espelage DL. (Eds.). Handbook of bullying in schools. New York: Routledge 2010. p.187-197.

12. Alikaşifoğlu M. Akran istismarı [Peer Abuse]. Turk Arch Ped. 2011;46(Suppl): 3134.

13. Carlyle KE, Steinman KJ. Demographic differences in the prevalence, co-occurrence, and correlates of adolescent bullying at school. Journal of School Health 2007;77(9):623-629.

14.Kapc1 EG. İlköğretim öğrencilerinin zorbalığa maruz kalma türünün ve sıklığının depresyon, kaygı ve benlik saygısıyla ilişkisi [Bullying type and severity among elementary school students and its relationship with depression, anxiety and self esteem]. Ankara Üniversitesi Eğitim Bilimleri Fakültesi Dergisi [Ankara
University Journal Database] 2004;37(1):113.

15.Mishna F, Alaggia R. Weighing the Risks: A child's decision to disclose peer victimization. Child Sch 2005;27(4):217226.

16.Wang J, Iannotti RJ, Nansel TR. School bullying among adolescents in the United States: physical, verbal, relational, and cyber. J Adolesc Health 2009;45:368-375.

17.Hesapçıŏlu ST, Yeşilova H. Lise öğrencilerinin zorbalığa ve zorbalara ilişkin duyguları, düşünceleri ve tutumları [Feelings, thoughts and attitudes of high school students toward school bullying and the bullies]. Anadolu Psikiyatri Dergisi [Anatolian Journal of Psychiatry] 2015;16(4):284-293.

18.Cook CR, Williams KR Guerra NG, Kim TE, Sadek S. Predictors of bullying and victimization in childhood and adolescence: a meta-analytic investigation. School Psychology Quarterly 2010;25:65-83.

19.O'Brennan L, Bradshaw CP, Sawyer AL. Examining developmental differences in the social-emotional problems among frequent bullies, victims, and bully/victims. Psychology in the Schools 2009;46:100-115.

20.Arslan S, Savaşer S. Akran zorbalığını önlemede okul hemşiresinin rolü [Role of School Nurse in Peer Bullying Prevention]. Maltepe Üniversitesi Hemşirelik Bilim ve Sanatı Dergisi [Maltepe University Journal of Nursing Science and Art] 2009;2(3):118-123.

21.Selekman J, Praeger SG. Violence in schools. In J. Selekman, School Nursing: a Comprehensive Text. Philadelphia: FA Davis. 2006. p.919-42.

22. American Academy of Pediatrics, Council on School Health. Policy Statement: The role of school nurse in providing school health services. Pediatrics 2008;121:1052-56.

23. Blosnich J, Bossarte R. Low-level Violence in Schools: Is there an association between school safety measures and peer victimization? Journal of School Health 2011;81(2):107-113.

24.King K. Violence in the school setting: a school nurse perspective. The Online Journal of Issues in Nursing 2014;31(19):35-43.

25. Vreeman RC, Carroll AE. A systematic review of school-based interventions to prevent bullying. Arch Pediatr Adolesc Med 2007;161(1):78-88. 
26.O'Moore M. Understanding School Bullying: A Guide for Parents and Teachers, Dublin. Veritas. 2010.p.23,32.

27.Hill NJ, Hollis M. Teacher time spent on student health issues and school nurse presence. J Sch Nurs 2012;28(3):181-186.

28. Georgiou SN. Bullying and victimization at school: the role of mothers. $\mathrm{Br} \mathrm{J}$ Educ Psychol. 2008;78:109-125.

29.Karataş H. İlköğretim okullarında zorbalığa yönelik geliştirilen programın etkisinin incelenmesi [Examining the effect of the program developed to address bullying in primary schools]. Yayınlanmamış Doktora Tezi, Dokuz Eylül Üniversitesi Sağlik Bilimleri Enstitüsü, Çocuk Sağlığı ve Hastalıkları Hemşireliği Anabilim Dalı, 2011, İzmir.

30.Pişkin M. School bullying: definition, types, related factors, and strategies to prevent bullying problems. Educational Sciences: Theory and Practic 2002;2(2):531-562.

31. Olweus D, Limber SP. Bullying in School: Evaluation and dissemination of the olweus bullying prevention program. Am J Orthopsychiatry 2010;80(1):124-134.

32. Albayrak S. Okulda uygulanan zorbalığ önleme programının zorbalığın azalt1lmasinda etkisi [The effect of the bullying prevention program implemented in the school on the reduction of bullying] Yayımlanmamış Yüksek Lisans Tezi, Marmara Üniversitesi Sağlık Bilimleri Enstitüsü, Halk Sağlığı Hemşireliği Anabilim Dal1, 2012, İstanbul. 